Literatura y Lingüística $\mathrm{N}^{\circ} 26$

ISSN 0716-5811 / pp. 229-246

\title{
Análisis pragmático de las máximas griceanas en textos orales y escritos*
}

\author{
Horacio Miranda Ubilla** \\ Marisa Guzmán Munita ${ }^{* * *}$
}

\section{Resumen}

Este trabajo analizó el comportamiento lingüístico de hablantes chilenos en un contexto de habla real, y describió diversas particularidades pragmáticas (Austin, 1962; Grice, 1967; Searle, 1969; Vanderveken, 1990). Se examinó el discurso oral y escrito, en su estilo formal e informal, recogido en los programas Tolerancia Cero y Morandé con Compañia, y de los textos emanados de los periódicos El Mercurio y The Clinic. El estudio permitió objetivar incumplimientos e inconsistencias, pero también regularidades y observancias; de manera que se levanta como una contribución al propósito de conocer la conducta lingüística de los chilenos.

Palabras clave: pragmalingüística, máximas conversacionales, implicatura conversacional, medios de comunicación masiva, intercambios dialógicos.

\section{Pragmatic analysis of Grice's maxims applied to oral and written texts}

\begin{abstract}
The aim of this study was the analysis of the linguistic behaviour of Chilean speakers in real communicative contexts considering their pragmatic implications. (Austin, 1962; Grice, 1967; Searle, 1969; Vanderveken, 1990). To this end, formal and informal, oral and written discourses were studied. They were represented by the TV programs Tolerancia Cero and Morandé con Compañia, on the one hand, and El Mercurio and The Clinic, on the other. The study allowed to objectivize the violation and observation of Grice's conversational maxims and the role of the conversational implicature to recover hidden messages. The result of this is an important contribution to know more about the linguistic behaviour of Chilean people.
\end{abstract}

Key words: pragmalinguistics, conversational maxims, conversational implicature, mass media, conversational exchanges.

Recibido: 11-12-2011 Aceptado: 07-07-2012

\footnotetext{
Proyecto elaborado para el Departamento de Investigaciones Científicas y Tecnológicas (DICYT) de la Universidad de Santiago.

** Doctor en Lingüística por la Universidad de Valladolid. Académico de la Universidad de Santiago de Chile. horaciomir@gmail.com

*** Mg. en Lingúística. Académica de la Universidad Católica Silva Henríquez. Chile. journalistmgm@gmail.com
} 


\section{Introducción}

Este artículo es el resultado de un proyecto de investigación de dos años, elaborado para el Departamento de Investigaciones Científicas y Tecnológicas (DICYT) de la Universidad de Santiago, del que se han presentado algunos avances en diversos congresos. ${ }^{1}$

El sustento teórico del estudio lo provee principalmente Paul Grice, por lo que el análisis se centra en pesquisar las inobservancias a las máximas conversacionales desarrolladas por este autor, apreciadas en los programas de televisión Morandé con Compañía y Tolerancia Cero, así como de editoriales de El Mercurio y titulares del periódico The Clinic. El objetivo fue explorar un corpus, conformado por enunciados orales y escritos, seleccionados de contextos formales e informales, para dilucidar qué mecanismos se activan en la recuperación de mensajes a través de las implicaturas conversacionales presentes en los intercambios dialógicos.

Atendiendo a la esencia de la propuesta de Grice, que argumenta que la interacción lingüística se realiza sobre una base cooperativa, se busca desentrañar los mecanismos pragmáticos que regulan la interacción, lo que se complementa con los aportes de Austin, Searle y Vanderveken. Teniendo esto presente, nos fijamos los siguientes objetivos para analizar dichas secuencias:

1. Identificar las máximas que se rompen en el corpus seleccionado.

2. Registrar los elementos no verbales asociados a esta inobservancia.

3. Analizar el proceso inferencial a través del cual se rescata el mensaje oculto de enunciados donde se han violado las máximas conversacionales.

En el presente artículo, se presenta una muestra de lo que fue esta investigación.

\section{Marco Teórico}

Todos sabemos que la comunicación tanto verbal como no verbal se constituye en la esencia del ser humano. Nos comunicamos todo el tiempo, y de diversas maneras en forma natural, sin tener conciencia

1 Nos referimos al último congreso de la Sociedad Chilena de Lingüística (SOCHIL) 2009 y al convocado por la Sociedad Nacional de Profesores de Lenguas Extranjeras en la Enseñanza Superior (SONAPLES) 2011.

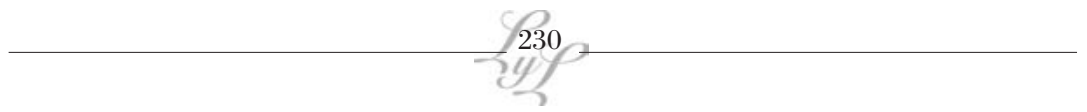


del código que usamos, con una creatividad y generatividad que ilustra la afirmación central de Chomsky (1957), cuando refiere la capacidad del ser humano para generar una cantidad infinita de enunciados, a partir de un número finito de elementos. Es, en definitiva, lo que nos diferencia de otras especies no humanas que, sin contar con el lenguaje estrictamente humano, se comunican con sus congéneres sobre la base de un repertorio limitado de señales.

Los estudios lingüísticos, al dar cuenta de las relaciones entre lenguaje y usuarios, enfatiza las implicancias socio-pragmáticas de los enunciados en contextos comunicativos, lo que ha enriquecido la comprensión del lenguaje al complementar con su aporte los estudios tradicionales basados en aspectos meramente lógicos, semánticos y sintácticos.

No cabe duda que con nuestra conducta lingüística trascendemos los límites de los significados semánticos convencionales, para incursionar en el mundo de los significados pragmáticos. Esto se manifiesta en las realizaciones cotidianas, en las que la carga pragmática de los enunciados puede dar lugar a mensajes muy distintos de lo que se expresó literalmente. Para el análisis de los diversos significados pragmáticos de los enunciados es menester contextualizarlos, distinguiendo a los participantes, la relación entre ellos, el tema, lugar, nivel de formalidad o informalidad de la situación, el conocimiento compartido de mundo e intención elocutiva del hablante, entre muchos otros aspectos. ${ }^{2}$ Dicho de otra manera, nuestros enunciados no son independientes de los contextos de situación en que los emitimos, más bien cobran vida en el contexto social al que pertenecen, y no fuera de éste.

\subsection{El Principio Cooperativo}

Para que un acto comunicativo sea exitoso, asumimos que los participantes actúan, generalmente, sobre una base social colaborativa, además de respetar las reglas del sistema de la lengua que comparten. Esta concepción de la comunicación humana lleva a Paul Grice a formular la teoría del principio cooperativo que, en la práctica, actúa como regulador de la conversación. Este principio, al que los interactuantes de una conversación adhieren, controla el desarrollo del intercambio y se expresa de la siguiente manera: "Haga su contribución a la conversación según sea

2 Emplearemos el término 'hablante' para referirnos al 'emisor', sea en su modalidad oral o escrita. 
necesario, en el momento en que ocurre, de acuerdo con el propósito y la orientación de la interacción lingüística en que usted participa o en la que se haya inmerso". (Nuestra traducción de Yule, 1996:37).

Esta teoría descansa en las máximas de cantidad, calidad, relevancia y modo que, dicho de una manera concisa, implica que los enunciados de los hablantes deben ser lo suficientemente informativos, veraces, pertinentes, claros y breves. Estas máximas se aplican de una manera diferente dependiendo de los participantes de la interacción comunicativa y del contexto de situación en que, por cierto, el hablante tiene que decidir qué grado de prioridad debe asignarle a cada máxima en desmedro de otra(s).

Las máximas griceanas, que se expresan en forma imperativa, son sólo regulativas. No son reglas constitutivas ni absolutas como las que gobiernan el sistema gramatical. Si un hablante no aplica el sentido lógico-literal de una máxima, como frecuentemente ocurre en una conversación, no transgrede ninguna regla gramatical de la lengua y, por lo tanto, no deja de manifiesto ninguna deficiencia en su competencia lingüística. Tal es el caso de una mentira y violar con ello la máxima de calidad (sea veraz), muy presentes en metáforas, ironías, expresiones idiomáticas, colocaciones, etc. De hecho, la normalidad es no mantener una absoluta adhesión a las máximas conversacionales en una conversación $y$, sin embargo, observar el principio cooperativo. Así, en el intercambio conversacional siguiente:

A: ¿Cómo te fue en la prueba de química?

B: Contesté todas las preguntas.

se puede inferir en una primera instancia, que B no está siendo lo suficientemente informativo ni pertinente. Se podría creer que no hay una intención real de respetar las máximas de cantidad y relación; no obstante, si aceptamos la premisa de que A y B actúan sobre una base cooperativa que sustenta el acto comunicativo, debemos asumir que B está, efectivamente, observando las máximas. No está simplemente dando información sobre la cantidad de preguntas que contestó sino que, además del significado literal, agrega otro significado que se deriva por implicatura, y éste es que "contestar todas las preguntas" implica entender que la prueba fue fácil y, por lo tanto, le fue bien. No sucede lo mismo con el ejemplo siguiente, donde la manifiesta transgresión a la máxima de cantidad, no permite que el oyente tenga acceso a la información requerida:

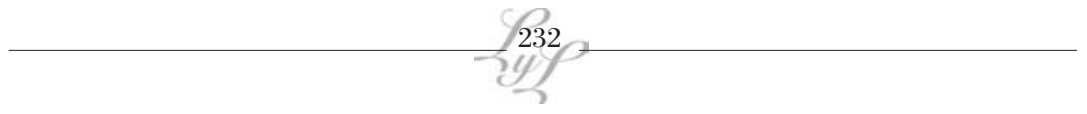


Jorge: Te vi con una rubia ayer. ¿Quién era?

Pedro: Y a ti, ¿qué te importa?

Al respecto, Grice propone la expresión implicatura conversacional (conversational implicature), principio de carácter descriptivo y no normativo, de las interpretaciones de los enunciados, para dar cuenta de la relación cooperativa entre hablantes y oyentes en una conversación, en que se comunica más de lo que dice. De esto se colige que el uso real y cotidiano del lenguaje posee un componente inferencial a través del cual el oyente o receptor deduce la intención comunicativa del hablante.

En el estudio, la violación de las máximas de calidad se apreció especialmente en el caso de las metáforas, que proporcionaron rico material para revisar las implicaturas y así, recuperar el mensaje subyacente. Esta inobservancia se representó tanto en el discurso oral como escrito y en sus estilos formales e informales. Tales fueron los casos manifiestos en los editoriales de El Mercurio y titulares del periódico The Clinic, así como en los programas televisivos Tolerancia Cero y Morandé con Compañía.

La investigación permitió describir cómo la recuperación exitosa de los mensajes está asociada a ciertos elementos lingüísticos, paralingüísticos y extralingüísticos, que se realizan de manera ostensiva y que los receptores deben desentrañar para captar con eficiencia lo expresado. Como aclara Grice "...un hablante viola ostensiblemente una máxima conversacional, y lo hace de manera tan manifiesta que el oyente lo advierte. Esa violación genera una inferencia de tipo estrictamente pragmático, es decir, una inferencia comunicativa"3 (Citado en Gil, 1999: 215).

Como se ha expuesto, las secuencias analizadas han sido tomadas de diversos medios de comunicación masivos, por lo que representan un contexto de habla real, donde fue posible apreciar la violación permanente de las máximas. Obsérvese un adelanto:

1. Máxima de cantidad: "Haga que su contribución no sea más ni menos informativa que lo estrictamente necesario de acuerdo al propósito de la conversación".

Ej. En una entrevista a un profesor desencantado con su trabajo, se le pregunta: ¿Cómo eran sus alumnos?

- "Eran niños, como todos" (The Clinic (291) del 29/04/2009, p. 10).

3 Las cursivas son el texto original. 
En este caso, se viola la máxima de cantidad al no dar la información que se requiere.

2. Máxima de calidad: "Que su contribución sea veraz. No diga lo que crea que es falso ni nada de lo cual usted no tenga conocimiento suficiente".

Ej. "En un ambiente de respeto y cordialidad, pero a la vez con firmeza y convicción en las posturas, se realizan las negociaciones entre el Gobierno y el Colegio de Profesores para que estos últimos depongan amablemente su paro" (The Clinic (296) del 04/06/2009, p. 12).

Los que hemos sido testigos de los problemas y desencuentros entre el gobierno y el gremio de profesores, sabemos que las negociaciones no han sido muy distendidas o amables. El lector puede interpretar correctamente que lo que se afirma no es verdad.

3. Máxima de relación: "Que su contribución sea pertinente al tópico de la conversación".

Ej. "Becas de intercambio estudiantil permitirán protestar en el extranjero" (The Clinic (402) del 14 de julio de 2011:2).

Uno podría preguntarse qué tienen que ver las protestas estudiantiles por mejoras en la calidad de la enseñanza en Chile con los programas de intercambio. Por implicatura, se entiende la ironía de que en vez de usar esa oportunidad para los efectos para los cuales se abrieron esos programas, se usa la ocasión para exportar las protestas.

4. Máxima de modo: "Sea claro y breve; evite las ambigüedades".

Ej. "Canal 13 le levanta nocheros a TVN" (The Clinic (367) del 28/10/2010, p. 3).

En este enunciado, se juega con la ambigüedad, al entrecruzar los significados de 'levantar nocheros' (que significa despertar a los guardias nocturnos para que realicen su función), y el de tentar a algunos rostros de Televisión Nacional por parte de Canal 13 con mejores incentivos.

La transgresión de las máximas conversacionales puede explicarse por razones culturales, relacionadas, por ejemplo, con mantener relaciones amistosas en buen pie, por temor, deferencia, etc. Eso lo sabe bien el hablante, quien, dadas las circunstancias, hará uso de su competencia lingüística-pragmática para determinar qué máxima privilegia y cuál o cuáles transgrede o deja de observar.

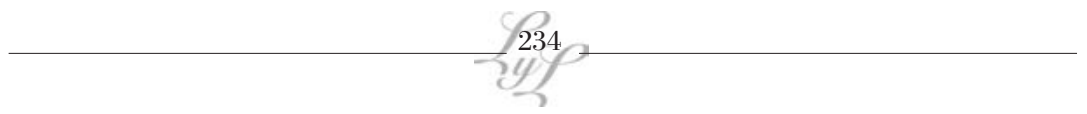




\subsection{Austin y su contribución al desarrollo de la pragmática}

El estudio de los Actos de Habla de John Austin (1962) permitió demostrar que decir algo es hacer algo. Su planteamiento señala que un acto de habla es un tipo de acción que si bien implica el uso de una lengua natural, no se sujeta exclusivamente a las reglas convencionales generales del sistema lingüístico, sino también a ciertos principios pragmáticos de pertinencia, que tienen lugar en un contexto de cooperación. Así, nuestra relación con el mundo se dibuja a partir del entramado permanente de actos de habla, pues en el intercambio cotidiano, por ejemplo, afirmamos y aseguramos (actos representativos); damos órdenes y suplicamos (actos directivos); expresamos diversos estados de ánimo (actos expresivos); asumimos compromisos y obligaciones (actos comisivos), o bien, el hablante logra cambiar el estado en que se encuentra alguna situación, como cuando se realiza el acto de excomulgar o bautizar (actos declarativos). ${ }^{4}$

Al desarrollar su teoría, Austin precisa que los actos de habla pueden segmentarse, como explica:

1) El acto locutivo: que se manifiesta a través del contenido proposicional.

2) El acto ilocutivo: que conlleva la fuerza pragmática del enunciado y la intención o fin concreto del acto de habla.

3) El acto perlocutivo: es el efecto que el enunciado produce en el receptor, en una determinada circunstancia.

Finalmente, hace una distinción entre las expresiones constatativas -que se pueden constatar y ser evaluadas, en consecuencia, como verdaderas o falsas- y las performativas en las que el hablante expresa verbalmente lo que está haciendo -estableciendo que los enunciados no sólo constatan hechos, sino que revelan acciones manifiestas en los actos de habla-. Estos últimos se evalúan como afortunados o no afortunados en la medida que la intención ilocutiva y la interpretación de un enunciado sea o no sea coincidente (felicitous/non felicitous).

\subsection{Los aportes de Searle y Vanderveken}

John Searle (1969) desarrolla el análisis de Austin sobre los enunciados performativos, centrándose en los actos ilocutivos, y explica que "hablar

4 Según la taxonomía de Searle. 
un lenguaje es realizar actos de acuerdo a reglas" (1969:46). Por lo tanto, los actos se realizan diciendo algo y aunque los enunciados poseen de suyo un contenido proposicional, difieren en su fuerza ilocutiva, lo que les permite constituirse en una aseveración, una pregunta, una orden o una expresión de deseo.

Searle asume que las fuerzas ilocutivas se pueden describir a través de una clasificación, que incorpora la variedad de actos representativos, directivos, comisivos, expresivos y declarativos, a través de los cuales es posible determinar la carga intencional que los hablantes realizan. Así, para que la comunicación sea exitosa, el oyente tiene que comprender la intención del hablante, lo que permite recuperar el significado. Esta recuperación estará fuertemente asociada al contexto social, y permeará las significaciones que los oyentes establezcan con determinados objetos, creencias, etc.

En esta misma línea, Daniel Vanderveken (1990) señala que el uso del lenguaje es una forma social de comportamiento lingüístico, que revela que, cada vez que un hablante emite un enunciado en un contexto determinado, emite uno o más actos ilocucionarios. Esto implica que la fuerza ilocucionaria se manifiesta en la sintaxis de las lenguas naturales reales de diversas formas, por ejemplo, en la puntuación y la entonación. Este autor desarrolla teóricamente el fundamento de la lógica ilocucionaria, y logra identificar 271 verbos performativos en la lengua inglesa, que permiten precisar con mayor exactitud los actos de habla.

En esta investigación, se complementaron las categorizaciones propuestas por Searle, con la taxonomía de Vanderveken, con el propósito de ampliar la mirada del análisis. Así, pudimos precisar diferencias, por ej. entre alabanza y cumplido u ordenar y pedir.

\subsection{Las metáforas conceptuales}

En 1980, los estudios de Lakoff \& Johnson convergieron en una investigación que permitió escrutar los mecanismos de inferencia que enmarcan la utilización de 'metáforas en la vida cotidiana', en un texto de ese mismo nombre. El desarrollo del concepto metáforas conceptuales aportó al análisis lingüístico por cuanto abrió una nueva dimensión para explorar el trasfondo de lo que comunicamos al utilizarlas. (Lakoff, 1992).

De esta manera, su uso en el habla real da pistas acerca de nuestra forma de pensar. En este estudio, la decisión de analizar las metáforas

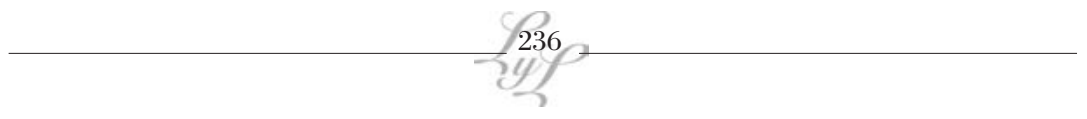


conceptuales manifiestas en el corpus seleccionado, permitió enriquecerlo desde diversas perspectivas.

A través de los ejemplos que se presentan, se buscó establecer la conexión entre metáfora y pensamiento. Si bien esta relación descansa en el procedimiento inferencial utilizado por los propios investigadores para resolver tales metáforas, desde el punto de vista teórico, el conjunto de enunciados extraídos del lenguaje cotidiano levantó el análisis en función de tres categorías, buscando interpretar la metáforas conceptuales de tipo estructural, orientacional y ontológico (Nubiola, 2000), a fin de llegar al concepto de la categoría misma.

\section{Antecedentes del objeto de estudio}

El objeto de estudio lo conformó el conjunto de enunciados orales y escritos, seleccionados de contextos formales e informales desde diversos medios de comunicación y programas emitidos por estos medios. Obsérvese el siguiente cuadro:

\begin{tabular}{|c|c|c|}
\hline & Lengua escrita & Lengua oral \\
\hline Estilo informal & The Clinic & Morandé con Compañía \\
\hline Estilo formal & El Mercurio & Tolerancia Cero \\
\hline
\end{tabular}

A continuación, caracterizaremos sucintamente a cada uno:

The Clinic es un periódico semanal que se caracteriza por su sello independiente y ácidamente crítico para informar del acontecer del país. Para ello, emplea un discurso irreverente y rupturista que, no pocas veces, cae en lo vulgar.

El Mercurio es la contraparte de The Clinic. Es un periódico de tendencia conservadora -el más antiguo del país- de circulación diaria. Se caracteriza por adoptar una docta formalidad, al dar cuenta del acontecer nacional e internacional.

Morandé con Compañía es un programa de televisión de entretención, dirigido a un público adulto que disfruta del género revisteril, en que el humor es asociado con el doble sentido y la picardía, los que, en esencia, forman parte de la identidad nacional de los chilenos

Tolerancia Cero es, también, un programa de televisión, pero dista mucho del estilo de Morandé con Compañía, por cuanto es de debate y conversación. Semanalmente sus destacados panelistas confrontan ideas entre sí y con sus invitados. Se caracteriza por un discurso que va desde 
lo culto formal a culto informal, en su búsqueda por abordar los diversos temas que impone la agenda noticiosa. ${ }^{5}$

\section{Metodología}

\subsection{Tipo de estudio}

Este es un estudio de tipo explicativo, que busca describir y correlacionar ciertos enunciados contextualizados del habla real chilena, con las máximas conversacionales de Grice.

\subsection{Corpus}

Se reunió material audiovisual proveniente de los programas de la televisión abierta Morandé con Compañía y Tolerancia Cero, del que se analizaron secuencias dialógicas escogidas dada su fuerza ilocutiva, a través de las cuales fue posible estudiar los factores manifiestos en las modalidades de uso del lenguaje en relación con las situaciones de habla. Este corpus se tabuló, analizó e interpretó de acuerdo a una pauta que permitió dar cuenta de ciertos elementos pragmáticos, en concordancia con las categorías propuestas por los teóricos que sustentan la investigación.

El corpus de los enunciados escritos lo constituyó, en el caso de El Mercurio, un conjunto de editoriales seleccionados para analizar los significados pragmáticos más allá de lo literalmente referido. En el caso de The Clinic, una serie de titulares a través de los cuales se propició el análisis pragmático de aquellos enunciados realizativos en los que se evidencia transgresión de las máximas de Grice. Cada enunciado se analizó en su contexto situacional, considerando el epígrafe que completa la información del titular, y la bajada, que complementa aún más el contexto situacional y que permitió profundizar el conocimiento de los mecanismos de recuperación, en cuanto a la observancia y rompimiento de las máximas conversacionales en este tipo de contexto informal.

En ambos casos, el material reunido se tabuló, examinó y explicó de acuerdo a una pauta ideada a fin de recoger el rompimiento de las

5 Al momento de realizarse esta investigación, el grupo lo componía Matías del Río, Fernando Paulsen, Juan Carlos Eichholz, y Fernando Villegas. Todos periodistas, exceptuando el último, que es sociólogo.

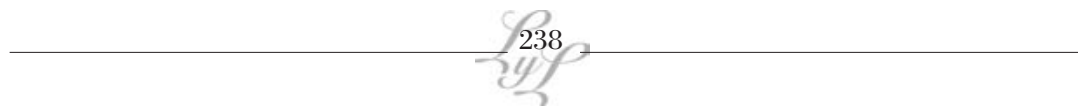


máximas griceanas y la concurrencia de las metáforas conceptuales de Lakoff (1992). ${ }^{6}$

\subsection{Objetivos}

El Principio Cooperativo y las Máximas que lo apoyan, permite contar con un modelo para analizar el comportamiento lingüístico chileno, para lo cual nos hemos fijado los siguientes objetivos.

1. Identificar y analizar las máximas que se rompen en textos escritos formales e informales.

2. Registrar los elementos no verbales asociados a esta inobservancia.

3. Examinar el proceso inferencial a través del cual se rescata el mensaje de enunciados orales y escritos donde se han violado las máximas.

4. Evaluar el modelo de Grice en muestras de textos escritos y orales chilenos.

\section{El análisis}

En un instrumento creado para estos efectos, se resumió toda la información necesaria para su posterior análisis. Para los efectos de este estudio, las muestras estudiadas correspondieron a:

- The Clinic: titulares de las páginas 2 y 3 considerando los epígrafes y bajadas

- El Mercurio: Sección Opinión, página 3

- Tolerancia Cero: Sección conversación entre panelistas e invitados

- Morandé con Compañia: Sección sketches

Como se muestra:

Fuente: The Clinic

Enunciado:

Los dueños de la mina San José dicen que era un buen lugar para trabajar.

"En ningún otro lugar logras un ascenso tan rápido"

Fecha: 28 de octubre de 2010

Estilo: Formal en un contexto informal

Acto de habla: Asertivo

Searle: Expresivo

6 Para efectos de este artículo, se expondrá una acotada muestra del análisis. Atendiendo a la esencia de la propuesta de Grice, que argumenta que la interacción lingüística se realiza sobre una base cooperativa, sólo consideramos aquellos enunciados donde se evidencia la violación manifiesta de las máximas conversacionales. 
Máxima violentada de Grice: Modo

Justificación: Se relaciona el ascenso con el atributo de promoción, y la ambigüedad se produce en contraste con el contexto en que esto se produce.

Modo: Indirecto*

Metáfora conceptual: Orientacional, por cuanto analoga la experiencia (el ascenso) con otra, (el concepto de 'arriba') de suyo positivo en este contexto, estableciendo la relación de la metáfora con la de constituirse en un 'buen lugar para trabajar'.

Contexto de situación: Rescate de los 33 mineros en el Norte de Chile. Las malas condiciones de trabajo de los mineros de la mediana y pequeña minería.

Comentarios: Se observa un toque de ironía al referirse a los pocos minutos que requirió traer a cada minero desde la profundidad a la superficie, en una misión de rescate conocida por el mundo entero en vivo y en directo. Se trata de una 'triste ironía' por cuanto tal ascenso nada tiene que ver con que sea 'un buen lugar para trabajar.'

Del análisis de los códigos verbales manifiestos en El Mercurio, encontramos que los elementos contextuales fueron vitales para recuperar lo que el emisor había querido comunicar.

\begin{tabular}{|c|}
\hline Fuente: El Mercurio \\
\hline Fecha:21 de junio de 2009 \\
\hline $\begin{array}{l}\text { Enunciado: } \\
\text { El clima político es obviamente influido por las opiniones de la población sobre la } \\
\text { marcha del país }\end{array}$ \\
\hline Estilo: Formal \\
\hline Registro: Culto \\
\hline Acto de habla: Opinión \\
\hline Taxonomía Searle: Representativo \\
\hline $\begin{array}{l}\text { Máxima violentada (Grice): Modo } \\
\text { Justificación: La ambigüedad surge de relacionar la 'marcha del país', con la idea de } \\
\text { avance. }\end{array}$ \\
\hline $\begin{array}{l}\text { Metáfora conceptual: La expresión 'clima político' es Ontológica, porque categoriza } \\
\text { la circunstancia que describe, en concordancia a una equivalencia de elemento. Por } \\
\text { otra parte, en la 'marcha del país' hallamos una metáfora que expresa la noción de } \\
\text { movimiento como una entidad que avanza; por lo que también es Ontológica. Cabe } \\
\text { señalar que, además, categoriza al hecho con una cualidad de objeto animado, y en } \\
\text { el contexto político del enunciado, analoga dicho movimiento con 'recorrido', no con } \\
\text { 'progreso'. }\end{array}$ \\
\hline Modo (directo/indirecto): Directo \\
\hline Estructura lingüística: Asertiva \\
\hline $\begin{array}{l}\text { Contexto de situación: El editorial analiza reciente encuesta sobre la percepción } \\
\text { económica del país. En éste se señala cuánto influye la clase política en la opinión de } \\
\text { la población, manifiesta en la encuesta CEP. }\end{array}$ \\
\hline $\begin{array}{l}\text { Comentarios: En el contexto de las elecciones presidenciales, y a propósito de la } \\
\text { encuesta CEP, el editorial levanta argumentos con los que relaciona los resultados de } \\
\text { esa encuesta y el rol de los partidos en campaña. }\end{array}$ \\
\hline
\end{tabular}

* Entenderemos el acto indirecto como el comunicar algo distinto a lo que literalmente se dice por un lado, y como la incongruencia entre forma y función, por otro. Así, una estructura interrogativa no es necesariamente una pregunta, ni el significado de una expresión, ha de reducirse a su dimensión literal.

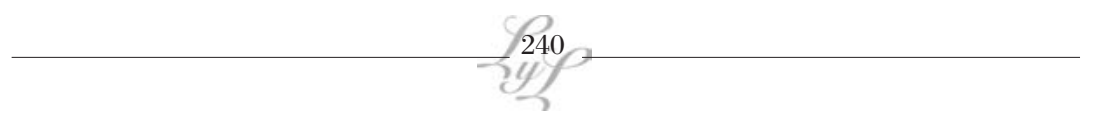


Para el análisis de la conducta oral, los aportes de los elementos no verbales (gestos, entonaciones de voz, miradas y uso del espacio) reforzaron y/o reemplazaron lo verbal, lo que facilitó las inferencias deducidas por el oyente. El programa Morandé con Compañia no sólo permitió recoger evidencia de la inobservancia de las máximas conversacionales de Grice, sino que develó de qué manera la violación permanente de estas máximas son la clave del éxito de este estelar y su sostenido rating.

El estudio tomó un conjunto de enunciados que al violar las diferentes máximas, conseguían provocar la risa de los televidentes. En este estudio descubrimos que dichos enunciados condensan la esencia del humor del que disfruta el chileno promedio, mezclándose el doble sentido permanente y la absoluta irreverencia, con un trasfondo que relaciona ciertos elementos textuales y contextuales con ciertos tópicos que se repiten como una constante: la degradación de la imagen femenina, la vulgarización del cuerpo desnudo, la instalación de estereotipos de belleza y perfección física, además de la permanente recreación humorística de problemáticas sociales, como el alcoholismo y drogadicción, así como la alusión permanente a lo sexual. Como se aprecia:

\begin{tabular}{l}
\hline Fuente: Programa Morandé con Compañía \\
\hline Segmento: "La hora del Pipo" \\
\hline Participantes: El actor Pablo Zamora, en el papel de Pipo, y Luis Jara, conductor \\
suplente del programa. \\
\hline Fecha: 23 de junio de 2009 \\
\hline Contexto situacional: En el marco de la presentación del primer capítulo de esta nueva \\
sección, Pipo hace publicidad a un helado. \\
\hline Enunciado contextualizado: \\
P: Les voy a presentar el nuevo helado, a sólo 990, se llama “chupa pipo" (risas del \\
público) ya lo saben. \\
L.J: ¿Cómo se llama el helado? \\
P: Chupa pipo, [...] es de chocolate con naranja. \\
L.J: Yo quiero uno. \\
P: Ahí tiene. (se lo entrega desde una cajita) \\
L.J: ¿Me puede dar otro? \\
P: (sorprendido) ¿Para quée \\
L.J: Para dárselo al Kike, pues... \\
P: (Lo queda mirando, mira al público, y comienza a entonar) ¡Chupa pipo, chupa pipo, \\
chupa pipo...(El público ríe y también se suma a entonar el estribillo) \\
\hline Taxonomía Searle: Expresivo \\
Acto de Habla: Aclama
\end{tabular}


Máxima violentada (Grice): Modo

Justificación: La expresión 'chupa pipo' no tiene correspondencia lógica con el hecho de que provoque risas. No resulta posible entenderlo, si no se cuenta con la referencia que nos llega del coa, ser 'chupa pico' que, como tal, alude al comportamiento de aquellas personas que están dispuestas a cualquier cosa con tal de congraciarse con sus superiores. Tal enunciado juega con la ambigüedad, por una parte, por la analogía fonética que establece entre ambas expresiones, y por otra, con que tal acto (ser chupa pico, como se denomina en coa al pene), P. cuestiona la amabilidad de L.J. cuando éste señala querer otro helado para llevarle al Kike.

Modo (directo/indirecto): Indirecto

Metáfora conceptual: Ontológica, porque categoriza la petición de LJ (llevarle un helado al jefe) con una acción relacionada con una persona (parte de ella: el pene).

Comentarios: En la secuencia, "P" corresponde a Pipo y "L.J." a Luis Jara. Los comentarios asociados, tanto paralingüísticos como del analista, están en cursivas. Los corchetes indican que ciertas partes de la secuencia fueron editadas.

En otro ámbito, exhibimos evidencias del análisis devenido del programa Tolerancia Cero, como tal, reconocido programa de conversación que aborda la contingencia nacional e internacional y se ha caracterizado por constituir un punto de referencia, propio de una línea discursiva liberal y de estilo formal. Con esta breve introducción se presentarán tres extractos de una muestra mayor, que abarca distintos períodos de este programa, para su análisis pragmático. Estos ejemplos giran en torno a las elecciones presidenciales de Chile del 2010, para lo que se seleccionaron dos secuencias dialógicas:

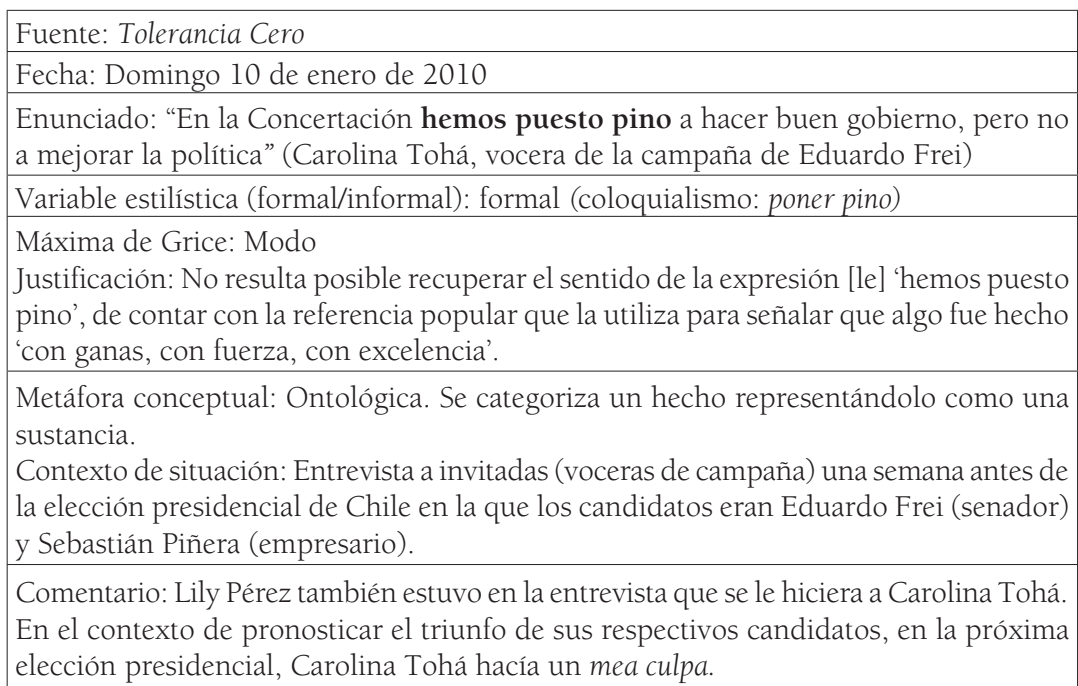

El contexto de situación en que está inserto este evento de habla, muestra a Carolina Tohá, vocera de la campaña de Frei, hacerle una crítica a la Concertación por no haber demostrado hacer bien su tarea. Es más

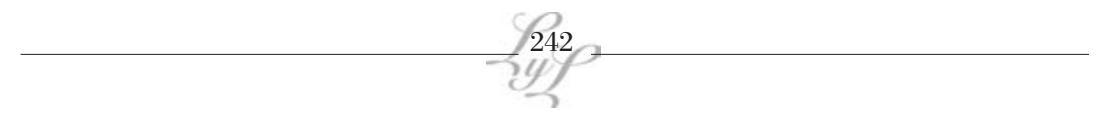


bien un acto expresivo, porque conlleva aspectos que tienen que ver con la afectividad. Quien no conozca el entorno que subyace a este evento comunicativo tendrá dificultades para, no sólo decodificar el texto, sino que también interpretarlo de acuerdo con las intenciones comunicativas de la hablante. La expresión "ponerle pino" es un chilenismo que significa hacer algo con ganas, esfuerzo, interés, etc. Toda la expresión es un mea culpa por no hacer bien las cosas, especialmente en lo referido a mejorar la actividad política tan criticada y denostada por gran parte de la población. La máxima que se transgrede aquí es la de modo.

\begin{tabular}{l}
\hline Fecha: Domingo 17 de enero de 2010 \\
Enunciado (español): "No ganó la derecha sino la ceguera de muchos" (Marco \\
Enríquez-Ominami, ex candidato presidencial en $1^{a}$ vuelta) \\
\hline Máxima de Grice violentada: Modo \\
Justificación: La ambigüedad se produce con la expresión 'muchos'. A través de un \\
modo indirecto, asevera que, el que los partidos políticos de derecha hayan ganado las \\
elecciones, no indica que son mayoría. Sostiene que los indefinidos 'muchos' votaron \\
por Piñera, no por compartir sus postulados, sino por su 'ceguera', o sea, por no haber \\
tenido conciencia crítica de la situación que el triunfo de la derecha implicará. \\
\hline Acto de habla: Crítica \\
\hline Taxonomía de Searle: Expresivo \\
\hline Metáfora conceptual: Ontológica. Se categoriza el hecho con una cualidad humana. \\
La expresión 'ceguera' al ser una traspolación del mundo de los impedimentos físicos \\
al de la contingencia política, adquiere un significado distinto; el de una incapacidad \\
de los electores de haber analizado correctamente los hechos, antes de sufragar en \\
mayoría, por la derecha. \\
Contexto de situación: Entrevista a dos senadores electos (Ricardo Lagos Weber y \\
Alberto Espina) y a un ex candidato presidencial de primera vuelta (Marco Enríquez- \\
Ominami) en la noche de la elección presidencial en la que se resultó como Presidente \\
electo, Sebastián Piñera. \\
\hline Comentario: El cierre de 20 años de gobierno de la Concertación y la alternancia de \\
un gobierno de derecha, generan enconados comentarios, en el contexto de que, tras \\
52 años, esta coalición recobra el poder político, en limpia elección. \\
\hline
\end{tabular}

Tras lo expuesto, debemos reconocer que pese a nuestro intento por apegarnos a categorías para orientar el análisis, la interpretación es un terreno abierto y dinámico que se articula en función de diversas variables: el grado de conocimiento del contexto de situación, la posesión de los referentes requeridos, el grado de interés por la situación, los elementos lingüísticos y extralingüísticos relacionados, las emociones involucradas, entre otros.

En el mundo de la pragmática nada es absoluto y, por lo tanto, no se apuesta a imponer nuestro criterio, sino a aportar con explicaciones que permitan comprender la percepción que cada uno pueda tener ante actos lingüísticos, en su contexto de uso. 
Como ya se ha afirmado, las máximas griceanas son sólo regulativas. No son reglas constitutivas ni absolutas, como las que gobiernan el sistema gramatical. Si un hablante no aplica el sentido lógico de una máxima, como frecuentemente ocurre en una conversación, no transgrede ninguna regla gramatical de la lengua. Por ejemplo, decir una mentira y violar con ello la máxima de calidad (sea veraz), no implica que el hablante manifieste deficiencias en su competencia lingüística. De hecho, aparentemente, no siempre se mantiene una absoluta adhesión a los principios cooperativos en una conversación. Siguiendo a José María Gil, se espera que la transgresión de las máximas sea manifiesta e intencional para ir al rescate del significado oculto. Así, el engaño, equívoco o suspensión del principio cooperativo, aun la contradicción entre las máximas, no impide que el principio inferencial de la implicatura conversacional actúe.

\section{Conclusiones}

Los ejemplos incluidos aquí constituyen una pequeñísima muestra de un corpus mayor, seleccionado de las cuatro fuentes abordadas, en un período de más de dos años de investigación.

Por un largo tiempo, estas fuentes han mantenido su misma línea y sello. De hecho, es con los que siempre se han identificado. Es la esencia de su existencia; la formalidad e informalidad, el apego a un discurso cuidadoso, relativamente conservador por un lado, y uno decididamente irreverente y coqueteando con la vulgaridad en muchos casos, por el otro. Tanto los programas televisivos (Morandé con Compañía y Tolerancia Cero) como los periódicos escritos (The Clinic y El Mercurio) tienen su público asegurado, que los sigue y apoya y que de alguna manera, representan la idiosincrasia del pueblo chileno. Esta observación amerita una explicación: podría haberse esperado resultados diferentes en atención a las características de cada una de estas fuentes y el tipo de público al que se dirigen, sin embargo, el principio cooperativo e implicatura conversacional de Grice, resultan adecuados para acoger los matices. Lo mismo ocurre tras analizar el interesante caudal de metáforas conceptuales recogidas, como tales, recurso que se levanta para agilizar el mensaje.

Quienes estén familiarizados con estos programas de televisión y medios periodísticos, podrán advertir que las licencias que se toman los medios más informales, reflejan en mayor frecuencia la transgresión de las máximas de Grice (calidad, cantidad, modo, relevancia). Sin embargo, pese a que por ejemplo, El Mercurio se caracteriza por un apego irrestricto a la forma y a la literalidad del lenguaje, el análisis demuestra

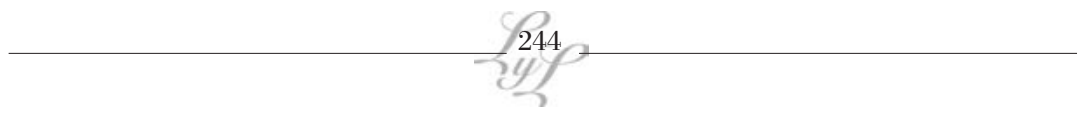


que aunque el grado de formalidad se manifiesta en su superficie, lo que se dice literalmente, no siempre es lo que se comunica.

La máxima de modo (sea claro, evite la ambigüedad) es la más violentada en los cuatro medios. Esta violación ostensible, abierta e intencional, nos permite no sólo decodificar, sino también interpretar adecuadamente lo que se quiso decir con lo que se dijo. Se reitera que el conocimiento de la situación compartida es crucial para la correcta interpretación. Alguien que no esté enterado de la contingencia nacional y local, que no tenga conocimiento de la gente involucrada en los hechos, incluso de los abundantes giros idiomáticos que se han transferido del coa al habla diaria, difícilmente podrá interpretar lo que se quiere comunicar.

The Clinic y Morandé con Compañía son, por lo señalado anteriormente, los medios que más rompen las máximas, especialmente la de modo, en cuanto hay una mayor ambigüedad en los enunciados performativos. En el programa televisivo, la inobservancia de las máximas de Grice es precisamente, lo que desata la hilaridad de los oyentes. Este humor se construye, por una parte, imponiendo un determinado rol a las mujeres que participan en el programa (todo versa en función a sus atributos físicos y sexualidad) y por otro, del trasfondo que permite relacionar los elementos textuales y contextuales, con tópicos que se repiten en el programa: la degradación de la imagen femenina, la vulgarización del cuerpo desnudo, la instalación de estereotipos de belleza y perfección física, la homosexualidad, así como la permanente recreación humorística de problemáticas sociales como el alcoholismo y drogadicción.

Hemos visto cómo el acto de habla indirecto es común a casi todos los ejemplos estudiados, dado que comunicar algo distinto a lo que literalmente se dice, permite el juego lingüístico de sintonizar la intencionalidad ilocutiva con la interpretación del oyente. Este acto indirecto se caracteriza por la incorcordancia entre forma y significado; de tal suerte, el significado pragmático al que adhieren los hablantes y oyentes chilenos, se constituye en la complicidad con el doble sentido, las metáforas y los modos indirectos.

Nuestra investigación es un ejemplo de las inmensas posibilidades de aplicación que tienen los modelos y propuestas de autores. Está claro que no hemos agotado en absoluto el tema; algunos aspectos los hemos tratado con cierta profundidad y otros los hemos soslayado dejando la puerta abierta, eso sí, para futuros estudios, en los que el diseño que hemos elaborado para describir el perfil de las situaciones de habla podría ser muy útil, como complemento de aquellas actividades que tienen como 
norte el desarrollo de las competencias lingüísticas y comunicativas: hablamos de una competencia pragmática.

\section{Bibliografía}

Austin, J. L. (1962). Cómo hacer cosas con palabras. Barcelona: Paidós, 1988.

Grice, H. P. (1967). "Lógica y conversación", en Valdés Villanueva, L. M. (ed.). La búsqueda del significado. Madrid: Tecnos, 1991.

Gil, J. M. (1999). Introducción a las Teorías Lingüísticas del Siglo XX. Buenos Aires: Melusina.

Lakoff, G. \& Johnson, M. (1980). Metaphors we live by. Chicago: University of Chicago Press. Editado en español por Cátedra como "Metáforas de la vida cotidiana", 1992.

Lakoff, G. (1992) "Contemporary Theories of Metaphor", in Ortony, Andrew (ed.) Metaphor and Thought (2nd edition), Cambridge University Press.

Leech., G. (1983). Principles of Pragmatics. Londres: Longman.

Miranda, H. (2002). La Cortesía Verbal en Textos para la Enseñanza del Español e Inglés como Lenguas Extranjeras. Alicante: Ed. digital Biblioteca Virtual Miguel de Cervantes.

Nubiola, J. (2000). Publicado en P. Pérez-Ilzarbe y R. Lázaro (eds.), Verdad, bien y belleza. Cuando los filósofos hablan de los valores. Pamplona: Cuadernos de Anuario Filosófico, nº 103, pp. 73-84.

Reyes, G. (1994). La Pragmática Lingüística. Barcelona: Montesinos.

Searle, J. (1969). Actos de habla. Ensayos de filosofía del lenguaje. Barcelona, México y Buenos Aires: Planeta-De Agostini, 1994.

Yule, G.. (1996). Pragmatics. Oxford: Oxford University Press

\section{Referencias electrónicas}

Con Searle: Actos de habla y Lógica ilocucionaria. [Doc. PDF]. Lógica (cap. 1 de Fundaciones de ilocucionarios Logic) reeditado en Lógica, Pensamiento y Acción. Documento en línea. URL http://www.uqtr.ca/ vandervk/cvdveng.htm

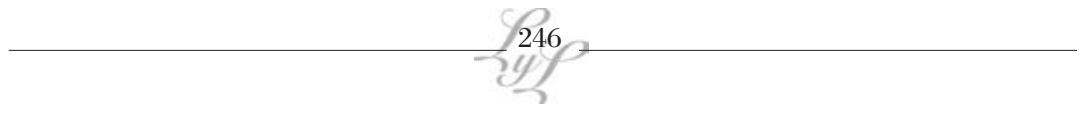

